International Journal of Current Advanced Research

ISSN: O: 2319-6475, ISSN: P: 2319 - 6505, Impact Factor: SJIF: 5.995

Available Online at www.journalijcar.org

Volume 6; Issue 5; May 2017; Page No. 3753-3757

DOI: http://dx.doi.org/10.24327/ijcar.2017.3757.0362

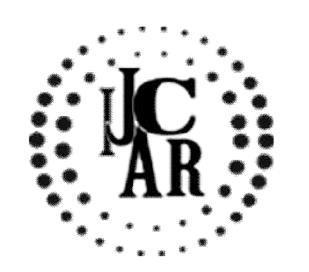

Research Article

\title{
PREVALENCE OF CONGENITAL HYPOTHYROIDISM IN MAKKAH REGION OF KINGDOM OF SAUDI ARABIA
}

\section{Shahnawaz Ahmed Sheikh1" ${ }^{*}$, Khawla Fahad AL-hazmi ${ }^{2}$., Hussam Jameel Khinkar² Shatha Awwadh Althobaiti ${ }^{2}$ and Nisreen Abdullah Rajeh ${ }^{3}$}

\author{
${ }^{1}$ Phenome Research Foundation, Mahamandal Nagar, Lahurabir \\ Varanasi, Uttar Pradesh-22001, India \\ 2Department of Biochemistry, College of Medicine, Umm Al-Qura University \\ Makkah-21955, Kingdom of Saudi Arabia \\ 3Department of Anatomy, Faculty of Medicine, King Abdulaziz University \\ Jeddah-21598, Kingdom of Saudi Arabia
}

\section{A R T I C L E I N F O \\ Article History: \\ Received $15^{\text {th }}$ February, 2017 \\ Received in revised form $12^{\text {th }}$ March, 2017 \\ Accepted $7^{\text {th }}$ April, 2017 \\ Published online $28^{\text {th }}$ May, 2017}

\section{Key words:}

Congenital hypothyroidism, Neonate, Newborn infants, Prevalence, Saudi Arabia.

\begin{abstract}
A B S T R A C T
Background: Congenital hypothyroidism $(\mathrm{CH})$ at birth is most commonly caused by disorder in thyroid gland development (dysgenesis) or thyroid hormone biosynthesis (dyshormonogenesis). Its early diagnosis and adequate treatment can prevent developmental retardation and other adverse consequences in infants. The objective of this study was to determine the prevalence of $\mathrm{CH}$ in Makkah province of Kingdom of Saudi Arabia (KSA).

Materials and methods: The medical records of 765 newborn infants who underwent laboratory screening for the determination of incidence of congenital hypothyroidism at AlNoor Hospital, over a period of one year (September 2014 to September 2015) were collected and analyzed.

Results: The overall prevalence of $\mathrm{CH}$ was $1.94 \%$ and it was higher in females $(1.04 \%)$ than males $(0.89 \%)$. Results showed significant differences in variables, viz. nationality, maturity, weight and co-morbity of newborn infants. However, it was found insignificant in gender. Thyroid stimulating hormone (TSH) levels exhibited insignificant differences in gender, nationality, maturity and weight. Free thyroxine (T4) levels in gender and maturity were found significant but it was insignificant in nationality and weight.

Conclusions: We concluded that the prevalence of $\mathrm{CH}$ in infants born in Makkah is almost similar to that of other countries reported earlier. It is also affirmed that TSH and T4 levels have important role in determining the incidence of $\mathrm{CH}$.
\end{abstract}

Copyright $₫ 2017$ Shahnawaz Ahmed Sheikh et al. This is an open access article distributed under the Creative Commons Attribution License, which permits unrestricted use, distribution, and reproduction in any medium, provided the original work is properly cited.

\section{INTRODUCTION}

Congenital hypothyroidism $(\mathrm{CH})$ is characterized by deficiency of thyroid hormone at the time of birth ${ }^{[1]}$. It is the most routine congenital disorder in childhood and is also considered as one of the most common preventable causes of intellectual disability ${ }^{[2]}$. The main cause of $\mathrm{CH}$ is the abnormal development of the thyroid gland (thyroid dysgenesis) or genetic defects in thyroid hormone biosynthesis (dyshormonogenesis) ${ }^{[1,2]}$. Thyroid dysgenesis is a sporadic disease, which accounts for $85 \%$ of cases of congenital hypothyroidism and remaining $15 \%$ of cases are caused by dyshormonogenesis ${ }^{[2]}$. Thyroid dysgenesis is

*Corresponding author: Shahnawaz Ahmed Sheikh

Phenome Research Foundation, Mahamandal Nagar, Lahurabir Varanasi, Uttar Pradesh-22001, India evident in three major forms i.e. thyroid ectopy, thyroid hypoplasia and athyreosis. Two-third cases of thyroid dysgenesis are caused by thyroid ectopy and it is twice more common in females ${ }^{[3]}$. Even though, the accurate etiology of thyroid dysgenesis is unknown, however, mutations in transcription factor genes regulating thyroid gland development [thyroid transcription factor 2 (TTF-2), NKX2.1 (also termed TTF-1) or PAX-8] would demonstrate these defects ${ }^{[4]}$. In the remaining one-third of cases, $\mathrm{CH}$ results from thyroid hypoplasia and absence of thyroid tissue (athyreosis). Dyshormonogenesis involves hereditary inborn errors in the enzymatic cascade of thyroid hormone synthesis and defects in peripheral thyroid hormone transport, metabolism or action ${ }^{[5]}$.

Congenital hypothyroidism often shows slight symptoms and numerous newborn infants remain undiagnosed at birth ${ }^{[6]}$. 
This deferred diagnosis results in the most acute outcome of congenital hypothyroidism ${ }^{[2]}$. The passage of maternal thyroid hormone passes across the placenta, which provides a protective effect, especially to the fetal brain but masks the clinical signs ${ }^{[7]}$. However, maternal and pregnancy history can give some indication of incidence for $\mathrm{CH}^{[1]}$. In some cases, gestation extends beyond 42 weeks ${ }^{[3]}$. Additional symptoms include constipation, hoarse cry, prolonged jaundice, feeding difficulty and lethargy ${ }^{[8]}$. Even some common types of $\mathrm{CH}$ have few moderately functioning residual thyroid tissue which obstructs the clinical diagnosis [9]. Hypothyroxinemia develops within several weeks of birth, clinical signs and symptoms of hypothyroidism become more apparent and puts neonatal brain at risk of permanent injury. Therefore, considering this vulnerability, it is essential to start treatment as soon as possible after birth ${ }^{[2]}$.

Congenital hypothyroidism is categorized into permanent $\mathrm{CH}$ and transient $\mathrm{CH}$. In permanent $\mathrm{CH}$, there is continuous deficiency of thyroid hormone and requires continuing treatment. While as in transient $\mathrm{CH}$, there is temporary deficiency of thyroid hormone, identified at birth, which is recovering to normal production of thyroid hormone. Transient $\mathrm{CH}$ is also associated with defects in other organ systems $^{[1]}$. Permanent $\mathrm{CH}$ can again be divided into permanent primary $\mathrm{CH}$ which results from dysgenesis or dyshormonogenesis and secondary or central $\mathrm{CH}$, results from the deficiency of thyroid stimulating hormone (TSH) ${ }^{[1]}$. Furthermore, some forms of $\mathrm{CH}$ classified as syndromic hypothyroidism are linked with defects in other organ systems [1]. Though the fundamental etiology of $\mathrm{CH}$ determines the type of hypothyroidism and whether there is involvement of other organ systems ${ }^{[1]}$.

The general prevalence of $\mathrm{CH}$ ranges from 1 in 3000 to 1 in 4000 newborn infants ${ }^{[10,11]}$. The occurrence of $\mathrm{CH}$ was found elevated in Hispanics, Asian Indians, Middle Easterners, Chinese, Hawaiians, Filipinos and Vietnamese than whites. While as black infants have very low prevalence of $\mathrm{CH}^{[11]}$. With the onset of the screening techniques at the time of birth, and more experience from national and international screening programs, it has turned clear that the prevalence varies by geographic region ${ }^{[12]}$. A study has found 2:1 greater occurrence in females than males, with an increased risk in infants with Down's syndrome ${ }^{[13]}$. In a study conducted in India, while screening 40,000 newborns, the prevalence has been reported to be 1 in $2640^{[13]}$. In United States, the occurrence (birth prevalence) of $\mathrm{CH}$ identified by newborn screening programs had almost doubled during past two decades, increased from 1:3985 in 1987 to $1: 2273$ in $2002^{[14]}$. During the previous two decades, there has been $37 \%$ raise in Asian births and 53\% raise in Hispanic births in the United States ${ }^{[15]}$.

While as in Kingdom of Saudi Arabia (KSA), the general incidence of $\mathrm{CH}$ was found to be 1:2759 live births with male: female ratio of $1: 1.8^{[16]}$. The accurate reason for this increase in incidence is ambiguous but the possible clarifications may be the changes in screening methods (lower TSH cutoff) and obtaining the screening specimen earlier (closer to the TSH surge after birth) ${ }^{[2]}$. CH seems to be linked with an increased danger of congenital malformations. It has been studied that $8.4 \%$ prevalence of extra congenital malformations were prevalent in 1420 infants with congenital hypothyroidism.
Most of these malformations were cardiac ${ }^{[17]}$. Other associated abnormalities consist of cleft palate, spiky hair, Down's syndrome, genitourinary malformations and neurologic disorders ${ }^{[17-19]}$. During neonatal period, acute hypothyroidism induces structural variations, including hypomyelination and defects of cell migration and differentiation, with long-lasting effects on performance and behavior $^{[20]}$.

Diagnosis of $\mathrm{CH}$ is made by biochemical screening of newborn. In developed countries where newborn screening programs are established, all infants are made to undergo newborn screening tests to diagnose the incidence of $\mathrm{CH}$. Still, only $25 \%$ of babies of worldwide birth population of 127 million are called for screening of $\mathrm{CH}^{[1]}$. For the rest of the $75 \%$ infants, especially concentrated in developing countries, clinical doubt of hypothyroidism calls for thyroid function evaluation ${ }^{[2]}$. Initial evaluation is carried out by laboratory screening to confirm diagnosis by thyroid function test: thyroxine (T4) and TSH measurement ${ }^{[21]}$.

Many studies have been done to determine the incidence of congenital hypothyroidism in Saudi Arabia. Even so, the alarming increase in the prevalence of congenital hypothyroidism indicates that more research should be carried out on the prevalence, diagnosis, causes and treatment of hypothyroidism. Therefore, in this study we have attempted to expand and replicate the observations of the previous studies. This retrospective study is aimed to evaluate the prevalence of congenital hypothyroidism in the neonatal lives in Makkah region of Saudi Arabia, by using the data collected from the records of the AL-Noor Specialist Hospital, Makkah, KSA.

\section{PATIENTS AND METHODS}

This retrospective study was carried out at Department of Biochemistry, Umm Al-Qura University, Makkah, KSA in collaboration with Al-Noor Specialist Hospital, Makkah, KSA. It includes 765 newborn infants who were subjected to newborn laboratory screening for determining the incidence of congenital hypothyroidism at Al-Noor Specialist Hospital over a period of one year (September 2014 to September 2015). The medical records of all these infants were reviewed and the data including sex, age, body weight, nationality, maturity/term (preterm or full term), maternal history of hypertension and diabetes, gestational age, maternal age, biochemical studies and radiological investigation were obtained after taking the proper consent from the subjects (parents of infants). This data was kept confidential and subjects involved in this study would not be identified in any way, to ensure that there will be no social, emotional or psychological damage to the subjects. This study was carried out according to guidelines of Institutional Research Ethics Board (IRB), Umm Al-Qura University, Makkah, KSA. These guidelines follow the national and international laws and policies of National Institutes of Health, USA). At the time of diagnosis, the sample was taken from the umbilical cord to perform the biochemical tests for checking the levels of free T4 and TSH using fluroimmunoassay, carried out by using commercially available kits (Mini VIDAS Report, BioMerieux, France). The normal range of T4 is 0.19-3.11 $\mathrm{nmol} / \mathrm{L}$ and TSH is $30-665 \mathrm{mUl} / \mathrm{L}$. After assessing the overall data of subjects, the newborn infants (male and female) with $\mathrm{CH}$ have been identified. The general parameters like weight, term, nationality, gender and family history of hypertension 
and diabetes of all the individuals were assessed and analyzed statistically. Further, clinical variable parameters like gestational age, maternal age, weight, TSH and free T4 were analyzed and interpreted. The TSH and free T4 levels were compared by considering gender (between male and female), nationality (Saudi and Non-Saudi), term (preterm and full term) and weight (low birth weight and normal birth weight). The resultant values were calculated.

Statistical analysis was done by using SPSS (statistical package for social science) version 22.0 (IBM Company, NY, USA) software package. Qualitative data was expressed as numbers and percentages. The significance for qualitative data was determined by using Chi-square test. Quantitative data were expressed as mean \pm standard deviation. Student's t-test was used as a test of significance. In all tests, the values $P<0.05$ were considered statistically significant.

\section{RESULTS}

During this study, the data of total 765 (100\%) newborn infants were collected and only $1.94 \%$ prevalence of congenital hypothyroidism was determined. The $\mathrm{CH}$ was more prevalent in females $(1.04 \%)$ than males $(0.89 \%)$ (Table 1).

Table 1 Prevalence of hypothyroidism among newborn infants and according to gender.

\begin{tabular}{cc}
\hline Prevalence & Percentage (\%) \\
\hline Among all newborn & 1.94 \\
Among male gender & 0.89 \\
Among female gender & 1.04 \\
\hline
\end{tabular}

Pertaining to the characteristics of newborn infants with $\mathrm{CH}$, although males represented $53.9 \%$ of all newborn cases with hypothyroidism, there was no significant difference $(p=0.058)$ found. However, there was a significant statistical difference $(\mathrm{p}<0.001)$ in nationality, Saudi $(66.7 \%)$ and Non-Saudi $(33.3 \%)$ identified with $\mathrm{CH}$. Maturity/term (preterm- $0.5 \%$ and full term-99.5\%) and weight (low birth weight- $0.5 \%$ and normal birth weight-99.5\%) of all the infants with $\mathrm{CH}$ $(p<0.001)$ were significantly different. The difference in the inborn co-morbidity (maternal hypertension and maternal diabetes) of the infants were found to be statistically significant (Table 2).

Table 2 Characteristics of newborn infants with congenital hypothyroidism

\begin{tabular}{|c|c|c|}
\hline Characteristic & Number (\%) & Test of significance \\
\hline \multicolumn{3}{|l|}{ Gender } \\
\hline Male & $412(53.9)$ & Chi-square $=2.15$ \\
\hline Female & $353(46.1)$ & $\mathrm{P}=0.058$ \\
\hline \multicolumn{3}{|l|}{ Nationality } \\
\hline Saudi & $510(66.7)$ & Chi-square $=93.2$ \\
\hline Non-Saudi & $255(33.3)$ & $\mathrm{P}<0.001 *$ \\
\hline \multicolumn{3}{|l|}{ Term } \\
\hline Preterm & $5(0.5)$ & Chi-square $=372.1$ \\
\hline Full term & $760(99.5)$ & $\mathrm{P}<0.001 *$ \\
\hline \multicolumn{3}{|l|}{ Weight } \\
\hline Low birth weight & $5(0.5)$ & Chi-square $=372.1$ \\
\hline Normal birth weight & $760(99.5)$ & $\mathrm{P}<0.001 *$ \\
\hline \multicolumn{3}{|l|}{ Maternal hypertension } \\
\hline Present & $17(2.2)$ & Chi-square $=402.2$ \\
\hline Absent & $748(97.8)$ & $\mathrm{P}<0.001 *$ \\
\hline \multicolumn{3}{|l|}{ Maternal diabetes } \\
\hline Present & $15(2)$ & Chi-square $=402.2$ \\
\hline Absent & $750(98)$ & $\mathrm{P}<0.001 *$ \\
\hline
\end{tabular}

Data were expressed as number and percentage. Chi-square test was used and significance was considered at $\mathrm{p}$ value less than 0.05 .
The quantitative data for the clinical parameters of newborns with $\mathrm{CH}$ is expressed as mean \pm standard deviation. The mean gestational age of all the infants was $39.25 \pm 1.72$ months in the range of 27 to 42 months, mean weight was $2.97 \pm 0.32 \mathrm{~kg}$ ranging from 0.75 to $4.6 \mathrm{~kg}$ and average maternal age was $24.49 \pm 4.05$ ranging in 18 to 33 years. For all the infants, the mean TSH level was $46.55 \pm 33.89 \mathrm{mUl} / \mathrm{L}$ in the range of 30 to $665 \mathrm{mUl} / \mathrm{L}$ and the mean free T4 level was $1.37 \pm 0.33 \mathrm{nmol} / \mathrm{L}$ ranging from $0.19-3.11 \mathrm{nmol} / \mathrm{L}$ (Table 3 ).

Table 3 Some clinical and lab parameters of newborn infants with congenital hypothyroidism.

\begin{tabular}{cc}
\hline Variables & Mean \pm SD range \\
\hline Gestational age & $39.25 \pm 1.72(27-42)$ \\
Maternal age & $24.49 \pm 4.05(18-33)$ \\
Weight & $2.97 \pm 0.32(.75-4.6)$ \\
TSH & $46.55 \pm 33.89(30-665)$ \\
Free T4 & $1.37 \pm 0.33(0.19-3.11)$ \\
\hline
\end{tabular}

Data were expressed as mean and standard deviation.

TSH and free T4 levels of newborns with $\mathrm{CH}$ were compared feature wise. The TSH levels of males and females are $63 \pm 143.11 \mathrm{mUl} / \mathrm{L}$ and $64.4 \pm 138.1 \mathrm{mUl} / \mathrm{L}$ respectively, but the difference was not statistically significant $(\mathrm{T}=0.07$ and $\mathrm{p}=0.94$ ). In contrary, free $\mathrm{T} 4$ levels of males and females were $1.35 \pm 0.31 \mathrm{nmol} / \mathrm{L}$ and $1.41 \pm 0.37 \mathrm{nmol} / \mathrm{L}$ respectively and the difference was statistically significant $(\mathrm{T}=0.28$ and $\mathrm{p}=.28)$. In case of nationality no significant difference was found in TSH $(\mathrm{T}=0.59$ and $\mathrm{p}=0.53)$ and free $\mathrm{T} 4(\mathrm{~T}=1.01$ and $\mathrm{p}=0.33)$ levels. The difference in the TSH levels of preterm and full term infants were non-significant $(\mathrm{T}=0.182$ and $\mathrm{p}=0.85)$ while, the T4 level of preterm infants was found statistically significant ( $\mathrm{T}=1.97$ and $\mathrm{p}=0.048)$. No significant difference was found in $\mathrm{TSH}(\mathrm{T}=0.225$ and $\mathrm{p}=0.82)$ or free $\mathrm{T} 4(\mathrm{~T}=0.28$ and $\mathrm{p}=0.79)$ levels in low birth and normal birth weight babies (Table 4).

Table 4 Comparison of thyroid stimulating hormone (TSH) and free thyroxine (T4) newborn with congenital hypothyroidism and some clinical parameters.

\begin{tabular}{|c|c|c|}
\hline Characteristic & $\begin{array}{c}\text { TSH } \\
\text { Mean } \pm \text { SD }\end{array}$ & $\begin{array}{c}\text { Free T4 } \\
\text { Mean } \pm \text { SD }\end{array}$ \\
\hline \multicolumn{3}{|l|}{ Gender } \\
\hline Male & $63 \pm 143.11$ & $1.35 \pm .31$ \\
\hline Female & $64.4 \pm 138.1$ & $1.41 \pm .37$ \\
\hline $\begin{array}{c}\text { Test of Significance } \\
\text { Nationality }\end{array}$ & $\mathrm{T}=0.07 \quad \mathrm{p}=0.94$ & $\mathrm{~T}=2.28 \quad \mathrm{p}=0.024 *$ \\
\hline Saudi & $68 \pm 152.4$ & $1.35 \pm .31$ \\
\hline Non-Saudi & $61.4 \pm 137.1$ & $1.36 \pm .32$ \\
\hline $\begin{array}{c}\text { Test of Significance } \\
\text { Term }\end{array}$ & $\mathrm{T}=0.59 \quad \mathrm{p}=0.53$ & $\mathrm{~T}=1.01 \quad \mathrm{p}=0.33$ \\
\hline Preterm & $74 \pm 171.3$ & $1.40 \pm .35$ \\
\hline Full term & $69.4 \pm 145.1$ & $1.29 \pm .39$ \\
\hline $\begin{array}{c}\text { Test of Significance } \\
\text { Weight }\end{array}$ & $\mathrm{T}=0.182 \quad \mathrm{p}=0.85$ & $\mathrm{~T}=1.97 \mathrm{p}=0.048^{*}$ \\
\hline Low birth weight & $68.77 \pm 132.11$ & $1.35 \pm .31$ \\
\hline Normal birth weight & $64.4 \pm 138.1$ & $1.28 \pm .37$ \\
\hline Test of Significance & $\mathrm{T}=0.225 \quad \mathrm{p}=0.82$ & $\mathrm{~T}=0.28 \quad \mathrm{p}=0.79$ \\
\hline
\end{tabular}

\section{DISCUSSION}

The current retrospective study was planned to determine the prevalence of congenital hypothyroidism in the neonatal lives in Makkah region of Saudi Arabia, by using the data collected from the records of the Al-Noor Specialist Hospital, Makkah, KSA. Data of 765 newborn infants who underwent screening 
for the incidence of $\mathrm{CH}$ was studied and observed. The prevalence of $\mathrm{CH}$ in female infants was found higher in comparison with the male infants. This observation is analogous to the findings of former studies where the incidence of $\mathrm{CH}$ was higher among females compared with males ${ }^{[22,23]}$. Other studies that have been carried out in KSA have also exhibited higher prevalence of $\mathrm{CH}$ in females than males (1:2759 live births with female: male ratio of approximately $2: 1)^{[16]}$. However, female: male ratio for prevalence of $\mathrm{CH}$ differs among different countries as reported in Estonia (6:1), Eastern Iran (1.4:1), Japan (1.2:1) and Saudi Arabia (3:1) ${ }^{[24-27]}$. This finding may be elucidated by the high parental consanguinity in KSA and the undiagnosed family history of $\mathrm{CH}^{[3]}$. It was also found that the number of Saudi nationals $(66.7 \%)$ with $\mathrm{CH}$ is more than the Non-Saudis (33.3\%). This significant difference may be due to different genetic, environmental and immunological factors as well as ethnicity ${ }^{[28,29]}$.

In this study, a significant variation in terms of prevalence of $\mathrm{CH}$ was found in the maturity/term (between preterm and fullterm) and birth weight (between low birth weight and normal birth weight) of infants with $\mathrm{CH}$. This finding indicates that the prevalence varied according to the maturity and weight of the neonates. This result in significant variation in maturity/term of neonates is supported by a previous study which reported that $\mathrm{CH}$ (transient) is considerably more prevalent among preterm infants than full term ones ${ }^{[30]}$. Similarly, a study described that low-birth-weight $(<2,000 \mathrm{~g})$ and macrosomic $(>/=4,500 \mathrm{~g})$ infants are at more risk of $\mathrm{CH}$ than normal birth weight of 3,000-3,499 $\mathrm{g}^{[11]}$. The high incidence of $\mathrm{CH}$ in preterm infants can be linked to insufficient or excessive iodine intake ${ }^{[31]}$. However, contrary to our results, a study conducted in Iran has found an insignificant variation in the maturity/term and birth weight of the infants with $\mathrm{CH}{ }^{[32]}$. We have also noticed significant variation in the incidence of $\mathrm{CH}$ co-morbidity, viz. maternal hypertension and maternal diabetes of $\mathrm{CH}$ infants. Although, this difference in prevalence may be due to several factors, but it may be assumed to be because of the genetic and familial disorders ${ }^{[32]}$.

In the present study, we have determined and compared the TSH and free T4 levels of newborns with $\mathrm{CH}$ in different variables. The comparison of TSH levels in males and females showed an insignificant difference while free T4 levels exhibited significant difference. This finding may be helpful in identification of $\mathrm{CH}$ in newborn infants as a study has reported that TSH and T4 levels may have predictive role for identifying permanent forms of $\mathrm{CH}$ from the transient forms ${ }^{[33]}$. Difference in the comparison TSH and free T4 levels between Saudi nationals and Non-Saudis were not found significant.This cause for this difference may be attributed to different genetic, environmental and immunological factors as well as ethnicity ${ }^{[28,29]}$. The difference in the TSH level of preterm and full term infants did not show any significance, however, the difference in free T4 level of preterm infants was found significant. Furthermore, TSH and free T4 levels in low birth and normal birth weight babies did not show any significant difference. In consistency to our results a study has reported the difference in the TSH and T4 levels among different variables of neonates ${ }^{[31]}$.
The incidence of transient $\mathrm{CH}$ can be attributed to the maternal factors such as excessive iodine intake, iodine deficiency, presence of antibodies against thyroid tissue during pregnancy or antithyroid medication ${ }^{[34-36]}$. In addition, the prevalence of permanent $\mathrm{CH}$ may be due to thyroid dysgenesis ${ }^{[37]}$. Thyroid dysgenesis is established as the main cause of permanent $\mathrm{CH}$ accounting for $79 \%$ of cases and dyshormonogenesis accounts for the remaining $21 \%{ }^{[33]}$.

\section{Limitations Of Study}

Since it is retrospective study on congenital hypothyroidism, so the data collected should have covered all the recorded characteristics of the neonates. However, the data did not consist the details of the type of $\mathrm{CH}$, actual TSH and T4 levels. The sample size was not sufficient to carry out a distinctive study.

\section{CONCLUSION}

We concluded that the prevalence of $\mathrm{CH}$ in infants born in Makkah, KSA is almost similar to that of other countries reported earlier. The prevalence of $\mathrm{CH}$ was more in females than males. The incidence of $\mathrm{CH}$ as studied by considering the different variables like maturity/term of neonates, nationality and birthweight, can be attributed to the genetic, immunological and environmental factors as well as ethnicity. This study also affirms that TSH and T4 levels have the important role in determining the incidence of $\mathrm{CH}$. Further studies are required to confirm the etiology, determine the prevalence, plan the management and treatment strategies for $\mathrm{CH}$.

\section{Acknowledgements}

We acknowledge Al-Noor Specialist Hospital, Makkah, KSA for providing data. We also acknowledge the support of Dr. Abeer Ahmed, Dr. Enas Hemdi, Dr. Sara Aletyani and Dr. Ameen Malki throughout this study.

\section{References}

1. Rastogi MV, LaFranchi SH. Congenital hypothyroidism. Orphanet $J$ Rare Dis 2010; 5(17): 1150-72.

2. Agrawal P, Philip R, Saran S, et al. Congenital hypothyroidism. Indian J Endocrinol Metab 2015; 19(2): 221-7.

3. Castanet M, Polak M, Bonaiti-Pellie C, et al. Nineteen years of national screening for congenital hypothyroidism: familial cases with thyroid dysgenesis suggest the involvement of genetic factors. J Clin Endocrinol Metab 2001; 86(5): 200914.

4. Al Taji E, Biebermann H, Limanova $\mathrm{Z}$, et al. Screening for mutations in transcription factors in a Czech cohort of 170 patients with congenital and early-onset hypothyroidism: identification of a novel PAX8 mutation in dominantly inherited early-onset non-autoimmune hypothyroidism. Eur $J$ Endocrinol 2007; 156(5):521-9.

5. Brown RS, Demmer LA. The etiology of thyroid dysgenesis-still an enigma after all these years. $J$ Clin Endocrinol Metab 2002; 87(9):4069-71.

6. LaFranchi SH. Hypothyroidism. Pediatr Clin North Am 1979; 26(1):33-51. 
7. Julvez J, Alvarez-Pedrerol M, Rebagliato $\mathrm{M}$, et al. Thyroxine levels during pregnancy in healthy women and early child neurodevelopment. Epidemiology 2013; 24(1):150-7.

8. Grant DB, Smith I, Fuggle PW, Tokar S, Chapple J. Congenital hypothyroidism detected by neonatal screening: relationship between biochemical severity and early clinical features. Arch Dis Child 1992; 67(1):87-90.

9. Delange F. Neonatal screening for congenital hypothyroidism: results and perspectives. Horm Res 1997; 48(2):51-61.

10. Haddow JE, Palomaki GE, Allan WC, et al. Maternal thyroid during pregnancy and subsequent neuropsychological development of the child. $N$ Engl J Med 1999; 341(8): 549-55.

11. Waller DK, Anderson JL, Lorey F, Cunningham GC. Risk factors for congenital hypothyroidism: an investigation of infant's birth weight, ethnicity and gender in California, 1990-1998. Teratology 2000; 62(1): 36-41.

12. Gaudino R, Garel C, Czernichow P, Leger J. Proportion of various types of thyroid disorders among newborns with congenital hypothyroidism and normally located gland: a regional cohort study. Clin Endocrinol (Oxf) 2005; 62(4): 444-8.

13. Desai MP. Disorders of thyroid gland in India. Indian J Pediatr 1997; 64(1): 11-20.

14. Harris KB, Pass KA. Increase in congenital hypothyroidism in New York State and in the United States. Mol Genet Metab 2007; 91(3): 268-77.

15. Hinton CF, Harris KB, Borgfeld L, et al. Trends in incidence rates of congenital hypothyroidism related to select demographic factors: data from the United States, California, Massachusetts, New York and Texas. Pediatrics 2010; 125(Suppl 2): S37-47.

16. Henry G, Sobki SH, Othman JM. Screening for congenital hypothyroidism. Saudi Med J 2002; 23(5): 529-35.

17. Olivieri A, Stazi MA, Mastroiacovo $\mathrm{P}$, et al.A population-based study on the frequency of additional congenital malformations in infants with congenital hypothyroidism: data from the Italian Registry for Congenital Hypothyroidism (1991-1998). J Clin Endocrinol Metab 2002; 87(2):557-62.

18. Law WY, Bradley DM, Lazarus JH, John R, Gregory JW. Congenital hypothyroidism in Wales (19821993): demographic features, clinical presentation and effects on early neurodevelopment. Clin Endocrinol (Oxf) 1998; 48(2): 201-7.

19. Kumar J, Gordillo R, Kaskel FJ, Druschel CM, Woroniecki RP. Increased prevalence of renal and urinary tract anomalies in children with congenital hypothyroidism. J Pediatr 2009; 154(2): 263-6.

20. Bernal J. Action of thyroid hormone in brain. $J$ Endocrinol Invest 2002; 25(3): 268-88.

21. American Academy of Pediatrics. Rose SR, Section on Endocrinology and Committee on Genetics, American Thyroid Association. Brown RS, Public Health Committee, Lawson Wilkins Pediatric Endocrine Society. Folley T, et al. Update of newborn screening and therapy for congenital hypothyroidism. Pediatrics 2006; 117(6): 2290-303.
A, Mirmiran

P, Moharamzadeh M, Hedayati M, Azizi F. A high prevalence of consanguineous and severe congenital hypothyroidism in an Iranian population. $J$ Pediatr Endocrinol Metab 2004; 17(9): 1201-9.

23. Tonacchera M, Banco M, Lapi $\mathrm{P}$, et al. Genetic analysis of TTF-2 gene in children with congenital hypothyroidism and cleft palate, congenital hypothyroidism, or isolated cleft palate. Thyroid 2004; 14(8): 584-8.

24. Dilli D, Czbas S, Acican D, Yamak N, Ertek M, Dilmen U. Establishment and development of a national newborn screening programme for congenital hypothyroidism in Turkey. J Clin Res Pediatr Endocrinol 2013; 5(2): 73-9.

25. Olney RS, Grosse SD, Vogt RF Jr. Prevalence of congenital hypothyroidism-current trends and future directions: workshop summary. Pediatrics 2010; 125(Suppl 2): S31-6.

26. Al-Maghamsi MS, Al-Hawsawi ZM, Ghulam GN, Okasha AM. Screening for congenital hypothyroidism in north-west region of Saudi Arabia. Saudi Med J 2002; 23(12): 1518-21.

27. Miyai K, Inaoka K, Miyagi $\mathrm{T}$, Committee for Newborn and Infant Screening in Osaka (CONISO). Further studies on episodic occurrence of congenital dysgenetic hypothyroidism in Osaka, Japan. Endocr $J$ 2005; 52(2):599-603.

28. Leger J, Marinovic D, Garel C, Bonaiti-Pellie C, Polak M, Czernichow. Thyroid developmental anomalies in first degree relatives of children with congenital hypothyroidism. J Clin Endocrinol Metab 2002; 87(2): 575-80.

29. Kaiserman I, Maytal A, Siebner R, Sack J. Effects of immigration on the incidence of congenital hypothyroidism. Eur J Endocrinol 1997; 137(4): 3569.

30. Uhrmann S, Marks KH, Maisels MJ, et al. Thyroid function in the preterm infant: a longitudinal assessment. J Pediatr 1978; 92(6): 968-73.

31. Chung HR, Shin CH, Yang SW, et al. High Incidence of Thyroid Dysfunction in Preterm Infants. J Korean Med Sci 2009; 24(4): 627-31.

32. Dorreh F, Chaijan PY, Javaheri J, Xeinalzadeh AH. Epidemiology of congenital hypothyroidism in Markazi Province, Iran. J Clin Res Pediatr Endocrinol 2014; 6(2):105-10.

33. Bekhit OEM, Yousef RM. Permanent and transient congenital hypothyroidism in Fayoum, Egypt: A Descriptive Retrospective Study. PLoS One 2013; 8(6): 1-6.

34. Bhavani N. Transient congenital hypothyroidism. Indian J Endocrinol Metab 2011; 15(Suppl 2): 117-20.

35. Wu RP, Hu YM, Jiang ZF. Practical Paediatrics, 6th Ed. Beijing. People's Hygiene Publishing House 1995; 1944-51.

36. Parks JS, Lin M, Grosse SD, et al. The impact of transient hypothyroidism on the increasing rate of congenital hypothyroidism in the United States. Pediatrics 2010; 125(Suppl 2): S54-63.

37. Brown RS. The thyroid gland. InBrook CGD, Hindmarsh PC. Clinical Pediatric Endocrinology. 4th Ed. Ames: Lowa: Blackwell Saince Ltd 2001; 288-320. 